\title{
The Communication As a Key Success in the Mexican Company "Frontera Imports" Located in the Territory US
}

\author{
Rafael Espinosa de los Monteros López ${ }^{1}$, Josefina Morgan Beltrán ${ }^{2 *}$, Ma. Luisa Leal García ${ }^{3}$ \\ ${ }^{I}$ Student of the Doctorate in Administration at the Autonomous University of Querétaro, Mexico. \\ ${ }^{2}$ Doctor of Administration and research professor at the Autonomous University of Querétaro, Mexico. \\ ${ }^{3}$ Doctor of Health Sciences and research professor at the Autonomous University of Querétaro, Mexico.
}

*Corresponding Author: Josefina Morgan Beltrán, Doctor of Administration and research professor at the Autonomous University of Querétaro, Mexico

\begin{abstract}
This research evaluates the importance of communication in one Mexican company located in Atlanta Georgia, USA, the problems that $g$ eneral to the work on foreign territory, this company with corporate name Frontera Imports, requires a communication effective in all areas and departments in an interrelated and precise way, considering that work is being done on American soil where different geography, language and culture play a very important role. The Mexican company Frontera Imports, It is a role model for Mexican or Latino companies seeking to do activities and businesses in the world and in the United States of North America. The methodology used is qualitative using Ethno methodology and the Case Study, and the objective is to analyze the internal and external communication of this organization, in order to identify this model of a Mexican company in the US with the intention of general confidence in businessmen and interested parties. On the feasibility of developing a company successfully in foreign territory, the proven hypothesis is the communication in "Frontera Imports" is a key factor of its competitiveness in the United States of North America.
\end{abstract}

Keywords: communication, culture, organization

\section{INTRODUCTION}

Frontera Imports is a company dedicated to importing grocery products, goods that are taken from Mexico to the United States of North America, such merchandise (products such as toast, sauces, soups, sweets, oils, etc.), is for consumption of the Mexicans (an average of 600,000 in that locality ). The products are consumed and demanded daily, making them reach the hands of Mexicans in that country requires communication and knowledge of needs and geographical areas.

The company is a business of thousands of dollars, there have been competitors, but they have left the business due to a lack of effectiveness and efficiency that translates into a lack of communication on American soil. Frontera Imports is a company that is dedicated to marketing Mexican products, that is, it buys products in Mexico and exports them to the United States of North America. It has 60 Mexican employees, including Buyers, Sellers, Storekeepers, Facturita, Chauffeurs and Administratives.

Purchasers of Frontera Imports are in Veracruz, specifically in Jalapa, also have buyers in the company in Atlanta, buy products that require a leads to a perfect communication. In addition, the purchasers are very linked to the vendors, which run through Atlanta to raise orders and through photographs send them to the billing department, the facturista asks the store that takes the order and that's where you see the role of buyers. When on the shelf fresh and enough of each requested type products are, it looks simple, but yet, when you live in a country other than that of origin, it is difficult to find well - known products and particular taste, miss and yearn. Frontera Imports tries every day to be in communication with its clients, to supply them with everything they need, there is a monthly magazine where offers are presented if demand is strong, the merchandise cannot cease to exist, and even more so when it appears in the catalog of offers, offers are to attract more orders, this leads to very accurate communication of the departments. 
The Communication As a Key Success in the Mexican Company "Frontera Imports" Located in the Territory US

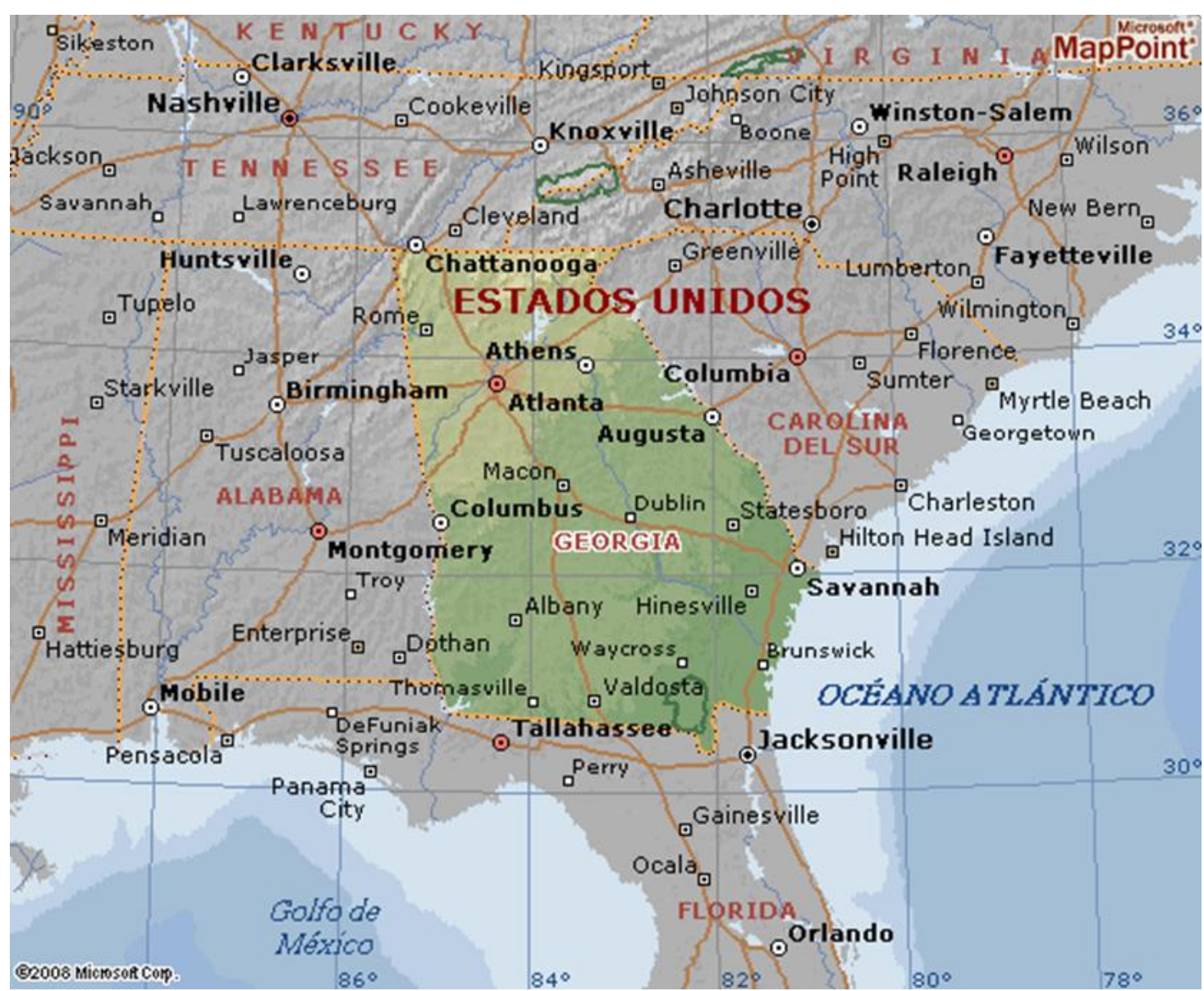

Figure1. Location of the company Frontera import

Source: google maps Atlanta Georgia (2020).

In the aspect of delivery of the goods, prepares store orders every day and a fleet of trucks from six in the morning, go out to distribute them to stores all estate Atlanta, can not miss any order, no product, the invoice must be well calculated, an error is very expensive, the merchandise is transported by road to the different counties and areas of this great city.

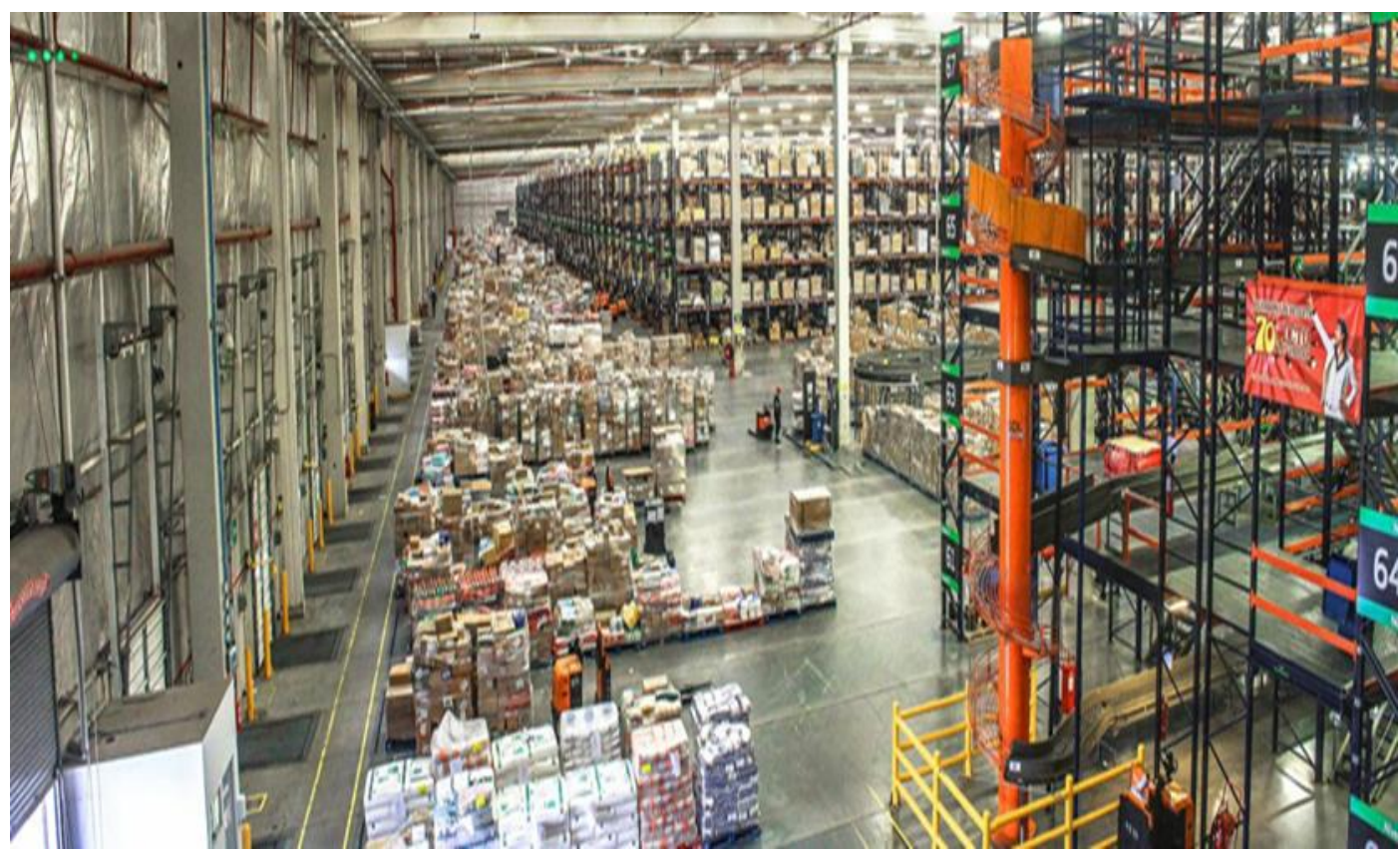

Figure2. Frontera Imports Warehouse.

Source: Photo Nave, Forest Par k. Atlanta. 


\section{COMMUNiCATion}

Escandel (2014) points out that to communicate is to transmit information through language and to communicate is to interact with others. Communication has this characterization and two facets: one of a linguistic type and the other of a social type. He also comments that humans communicate through language, languages are codes, and therefore, humans communicate by encoding and decoding messages. A code is a conventional system that establishes constant pairings between signals and messages. At Frontera Imports this is essential to develop daily work, since two languages are mixed, Spanish and English normally, although sometimes they are related to Russians, Indians, Japanese, because the United States is a country with a great number of inhabitants from different countries .

Rodríguez (2005), in Theories of communication, comments that " Communication processes always involve interrelationships of people who share information with each other, through the construction, emission and reception of messages, the elements that make up these processes are the source, the message, the channels or media, the receiver, the effects and the feedback. "

Palomino (2011), mentions that disasters due to bad, ineffective or non-existent communication can number in the thousands, in all areas of life, communication must be understood and used mainly as a resource, which is done in keys and codes basically"

Communication is not only a process that seeks to ensure mutual understanding, but also a resource that seeks development opportunities in individuals and organizations. Man permanently interacts with his fellow beings by exchanging information that affects them mutually. This ebb and flow of modifications (information) can be called experience, Pinilla (1972) says about it "In this experience between human beings, who it is called communication, actions, knowledge, feelings and attitudes are expressed through movements, gestures, instrumental actions and symbols loaded with meaning called language".

This communication includes tangible and intangible elements, the former include instrumental actions such as speaking, gesturing, or modifying their environment, the latter encompass psychic activities such as knowledge, in one way or another, and both elements are powerful and effective in communication. As for its etymology, the word communication comes from the Latin comunicare, which means "to share" or to make common.

At Frontera Imports, these processes are carried out in an orderly manner but always with great adherence to the procedure manuals. Pizzolante (2003), in Reason and Words, says "Most people do not keep reality in three dimensions, but they reproduce in two dimensions. The business communication is strategic to the extent that it is known where it is and where it wants to go. "

The corporate culture at Frontera Imports has particular ways of being and doing business as a whole: human, physical, emotional and social capital. It is important to add science to the art of communicating, as pointed out by Pizzolante (2003): the environment, contour and painting, this is the geometry of communication- From the geometry of the image to the geometry of communication. The first dimension of communication to consider refers to the business environment, the second dimension to the business environment and the third dimension to the business environment. Environment is what surrounds or surrounds the company. Contour: that tangible or intangible surface that separates the external of the company from the internal, that is to say seen from the outside, is the external edge that voluntarily or not communicates the particular features of the business personality, of communication and receives the name of corporate identity. To complete the geometry of the body of the company, the entrepreneurial strength conditions and anchors what the company is and can be, in the volume is enclosed the way of being and doing things in an organization, the lifestyle of a human being that, shared with others, within the company, characterize it and make it particular. Corporate identity is the personality that is built for themselves itself an organization of individuals, it is the way to make tangible and approach the attributes and values of a company conscious power of a strategic vision. The strategic identity, in the corporate world, is the personality that the company deliberately wants to build for itself and that, interpreted by its human capital, builds the impression and image that the company requires to fulfill its business plans. 


\section{Culture}

The culture as a strategy comparative and competitive a company is a powerful differentiator element for achieving the goals and succeed. Culture is the way of being and doing things, they are characteristic features that influence the way you think and act individually or with others.

Considering Costa (1999) "The fundamental vectors in the image management in the company are Corporate Identity, Organizational Culture., Global Action., Integrated Communication and Public Image". Furthermore, on identity, Costa (1999) mentions that it is the first essence of the company, Identity is a noun, it designates a substance or essence that is in the nature of things that exist in the environment, and identifying is a verb, an action.

For his part, Schneider (1990), provided a reflective analysis and integration of the development of theory and research of organizational culture, and a decade later, Pettigrew (1979), introduced the concept of organizational culture in the literature, his conclusions of this book were: "The most serious cause for concern is the lack of empirical study of organizational culture in the 1980s," Pettigrew, (1990, p. 417).

Xie (2002) comments that 1 to management personnel in companies financed abroad is a difficult problem that every manager find as a result of different system of personnel management, organizational system and monitoring system, many problems arise resulting therefrom e $n$ view of this, a solid company financed abroad must build more so an effective system to promote healthy development, including language training, acquisition of foreign knowledge and the establishment of corporate culture.

Traditional companies operating only within the borders of individual countries are very rare these days. Culture and cultural differences play an important role in international companies, the work of multicultural teams and international meetings. Workers, who are willing to admit, understand and respect the cultural differences of other nations and are willing to take useful steps, have a great advantage in performing tasks in a multicultural environment.

If want to succeed in the demanding competitive environment, 1 to intercultural management should not be considered as a marginal area, but as an area both internationally and nationally. The trend of development in this area advances towards the convergence of individual nations and the communication and understanding of intercultural differences that represent a possible way of achieving mutual cooperation, beyond the contemporary borders of individual states or groups. Until now, intercultural communication techniques have been shown to be of great importance in the management of companies financed abroad. Each company must pay sufficient attention to intercultural barriers and use the most appropriate method to predict, avoid and resolve the conflicts caused by these intercultural barriers.

An analysis by Van Dijk (2000), in Discourse as social interaction, says that in different societies people not only speak different languages and dialects, but use them in radically different ways. In some societies, conversations are curled with disagreements, voices are raised, and emotions are visibly externalized. In others, people conscientiously avoid the dispute, speak in soft, even tones, and take care of any display of their inner personality. In some parts of the world it is frowned upon to talk when someone else is talking, while that in others, this is expected behavior in any conversation.

The most influential approach in cultural and discourse studies is known as "communication ethnography." Communication ethnographers documented speech fact patterns in a wide range of cultures. His preferred methods of collecting information are participant observation and consultation with native speakers. Another aspect is marked by López (2012) in Culture and communication: a complex relationship, contributions to the Social Sciences, points out that:"Communication is inseparable from culture, and on the other side of the same coin, one cannot exist without the other, culture is communication and communication is culture".

\section{COMmunication And Culture Relationship}

The relationship between culture and communication is paradoxical, if culture is a social fact there is no culture other than manifested, transmitted and lived by the individual, but this mutual dependence has intensified within the cultural industries, despite their sectoral dynamics, the relationship culture - 
communication is ahistorical social process. Communication is a complex, special type of activity and its motive is the interaction, transmission or influence on the other member of the communicative relationship (Cruz, 2001), and the human fact occurs thanks to joint activity and is perpetuated and guarantee through the social process, the individual, at the time of his birth, is only a candidate to be a man, so it is necessary to learn to be a man in action and communication with other people.

For Sánchez (2016), in Reason and Words, the word communication comes from the Latin communis, which means "common". Also in Castilian the radical "common" is shared by the terms communication and community. This etymologically indicates the close relationship between communicating and being in community. For there to be communication, a shared system of referring symbols is necessary, which implies an exchange of common symbols between the people involved in the communication process.

Culture is the set of distinctive features, spiritual and material, intellectual and affective, that characterize a society or social group in a given period, the expression also encompasses ways of life, ceremonies, art, inventions, technology, value systems, rights fundamental of the human being, traditions and beliefs. Through culture, man expresses himself, becomes aware of himself, questions his relationships, seeks new meanings and creates works that transcend him.

Once established that business organization is a culture, the tools for its study can be as varied as those used in the study of social culture, two approaches to this are the elitist or authoritarian and the egalitarian or democratic, to enter the analysis of the relationship between organizational communication and organizational culture.

Another perspective of communication and organizational culture is presented with Guzman Paz (2012), Organizational Communication, who points out that: The communication and organizational culture are closely related. The concept of culture has entered the jargon of organizations with force in recent years, and increasingly linked to communication, in fact, a very widespread way of understanding culture is as a set of shared meanings that provide a common frame of reference and, therefore, similar patterns of behavior.

In the organization, the means of transmission and reinforcement of culture are multiple: symbols, behaviors, policies, procedures and norms, facilities and technology, to name just a few. The concepts indicated by Guzmán Paz (2012) are basic for the daily work at Frontera Imports, communication is a shared responsibility; as everyone in the organization communicates, communicating well is everyone's responsibility, although some must play a greater role in this regard due to the position they occupy or the information they handle. Therefore, the development of people's communication skills, at different levels and areas, has become a priority, especially now that organizations are experiencing fundamental changes.

Man since ancient times has been aware that efficiency can only be obtained through order, as well as the coordination of the operating resources of a social organism, human beings have belonged to organized formal and informal groups since their origins, in such a way that it is almost impossible to imagine them separated from each other, the organization is a process focused on achieving an end, which was previously established in the planning phase.

Organizing action becomes necessary as more people's efforts must be coordinated; Channels must be established to understand each other and engage in a complex of diverse tasks. The organization, expressed as a set of formalized relationships and behaviors between two people seeking to achieve something in common, determines the expected behavior, adding other important relationships, although it is true, man has managed to perfect the ways of organizing and better managing resources. Material, human and financial. The contributions of Frederick Taylor and Max Weber are innumerable.

Therefore, it is convenient to know the main schools and their respective theories about organizational behavior to know how to organize work efficiently, how to obtain greater productivity, how to reconcile the goals of a company with those of the staff to obtain better results and opportunities for both. Parts and how different parts of the organization are influenced, etc.

There is an enormous number of schools, approaches and currents within the study of organizations, which can be summarized in four fundamental theoretical schools: classical, humanistic, systems and contingency. 


\section{MAterials AND Methods}

As observed, communication in this company has several meanings and levels; from the interrelated departments in the operation and levels, such as the director, department heads, among others.

Communication must be respected, a message cannot be left unattended, an order is very important because it is the image of the company, the order is the message, the issuer is the customer but it becomes double action when the seller sends it to billing and billing to the warehouse and warehouse to shipments; it becomes a service process, where the interrelation between the message generator and the last one to fulfill the order is communicated by different means: for example, email, shortwave radio, cell phone, paper messages, but above all by the procedure manuals that serve as a guide for those involved in daily activity.

Each of the integrant is the company requires to know that if you omit the communication can be converted into chaos, 1 os channels of communication must be released and does not block two and should clarify the messages served by possible communication problems.

This article was developed using a qualitative methodology, which is understood as "a category of research designs that extract descriptions from observations that take the forms of interviews, narrations, field notes, recordings, audio transcripts and video, cassettes, records of all kinds, photographs or films and artifacts.

Specifically one looks at the Ethno methodology, which tries to study social phenomena incorporated in the speeches and actions through analysis of human activities, The distinctive feature of this lies method in its interest to focus on the study of the methods or strategies employed for people to build, give sense and meaning to their practices everyday social s, 1 to Ethnomethodology proposes that change should be measured in qualitative terms and seen through the eyes of the author.

The ethnographer examines the ideas and practices, taken for granted, that determine the way in which lives are lived and constructed in organizational contexts; Through what people say and do, it is possible to understand the way in which daily routines constitute and reconstitute organizational and social structures. Ethnography provides in addition to the kind of useful data to link these processes at the micro level, interact with structures at the macro level. It is worth remembering that another ethnographic method, observation, was used since the anthropologist W. Lloyd Warner, who was a disciple of Malinowski, Radclife Brown and Lowie and in turn influenced Roethlisberger and Dickson, suggested that the group of the work could be examined as if it were a small society, capable of submitting to the observational techniques of field study. This new method, by collecting detailed information about workers and their relationships with each other, led to the affirmation that for the first time in organizational research a systematic description of the social organization of a work group was being produced.

The independent qualitative variable is the communication, seeking to understand why the communication is paramount in Frontera Imports, variable communication refers to that quality observed as a feature in the organization and is treated by the company with some strategy to not suffer negative and harmful effects in the entity.

According to Hernández (2005), in Research Methodology the hypothesis in a qualitative research that is obtained during the research process, is generated and refined as the work progresses and more data is collected; the hypothesis is modified based on the researcher's reasoning. In this work, according to Hernández (2005) and based on the data obtained, the hypothesis is that communication at Frontera Imports is a factor of competitiveness in the United States of North America, due to the results obtained.

\section{RESUlts}

The results of this article, where the main topic is communication as a fundamental variable in the process and operation of the Frontera Imports company, a company of Mexicans in American territory, generates great attention for how it will respond in another scenario that is not His own, the approach of observing the media in the different activities of this company is of utmost attention to achieve results and have a model that could give a control parameter in future companies that seek commercial activities in this great country, the fact social that is observed is in relation to the 
communication that is manifested with the companies and with the Mexican community that lives in American territory and that thanks to Frontera Imports they do not feel alien to their identity as Mexicans. Thanks to communication and facing the barriers to it, an activity is carried out that is necessary to supply these people.

The results show that communication is action and that there is an inseparable relationship between communication and organizational culture. In addition, a qualitative methodological analysis is presented to highlight the need for adequate communication and to reinforce communication processes with all of its elements, the research aims to contribute as a contribution to the activities of companies seeking to operate in global settings.

\section{Thanks}

This article was carried out thanks to the great support and understanding of CEO Isidro Candelario, who, with his words, his attentions and his interest, was achieved.

Also to her Daughter Jazmín Candelario, every day that was used to carry out the investigations she always collaborated, she even invited us to breakfast. Thank you.

To all the personnel of the company Frontera Imports, Warehousemen, Drivers, Sellers, Facturists, Administrators, Buyers. Each of them great people.

To Dr. Josefina Morgan Beltrán, Postgraduate Director of the Faculty of Accounting and Administration of the Autonomous University of Querétaro, for all her patience and attachment to achieve this material.

\section{REFERENCES}

[1] Escandell V. and M. Victoria (2014). Communication. Spain, Akal SA

[2] Rodríguez G. I. (2005). Organizational Communication Theories, Venezuela, Gestiopolis.

[3] Palomino (20 1 1). Organizational Development, Pearson.

[4] Pinilla, A. (1972). Human and labor relations in the Company. Barcelona: Editores Técnicos Asociados, SA

[5] Pizzolante (2003). The Geometry of Business Communication, Reason and Words , Mexico Rev. No. 34

[6] Costa, J (1999). Communication in action, Spain, Paidós

[7] Scnnneider (1990). Organizational climate and culture

[8] Pettigrew (1979). On studying organizational cultures. Administrative science quarterly, 24 pp 570-581

[9] Xie , J. (2002). The Barriers to Communication. China, Rev. Academi Journal, Vol. 4

[10] Van Dijk , (2000). T. Discourse as social interaction. Spain Gedisa

[11] Lopez H., M.; Lopez. M., Lopez M. L. (March 2012). "Culture and communication a complex relationship" in Contributions to the social sciences. Rev. P. 1-10.

[12] Cruz, BY and Fernández, P. A. (2012). Theoretical positions around organizational communication. www.eumed.net/rev/cccss/20/

[13] Sanchez. M. (Dec. 2016) Reason and Words, Mexico. ITESM, Rev.

[14] Guzmán Paz, V. (2012). Organizational communication, Edo. From Mexico, Third Millennium Network

[15] Hernandez S. R. Fernandez, P. B. (2006) Research methodology, Mexico, Mc Graw Hill.

\section{AUTHORS' BIOGRAPHY}

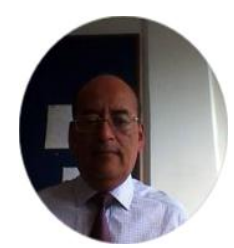

Master Rafael Espinosa de los Monteros, with 30 years teaching subjects in Administrative and Business areas. in universities such as the Autonomous University of Mexico.is a professor at the Autonomous University of Queretaro, in Mexico, currently coordinator of the Master in International Business.

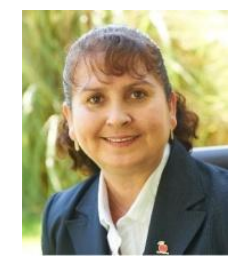

Dr. Josefina Morgan Beltrán, is a full-time professor and researcher at the Autonomous University of Querétaro, Mexico, she has a doctorate in Administration and a postdoctoral degree in Education and is a member of the National System of Researchers at Conacyt México; The lines of research are related to Organizational 

the Territory US

Competitiveness, Knowledge Management, Human Capital and Organizational Culture.

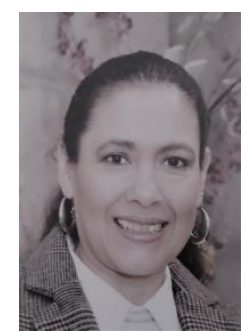

Dr. Ma. Luisa Leal García, Mexican, with a doctorate in Health Sciences, research professor at the Universidad Autónoma de Querétaro, author of books, chapters and articles, international speaker, received the 2009 National Award for Human Resources from The Society of A.C. Applied Psychology, the National Award for Labor Research 207 by the Ministry of Labor and Social Welfare, had the Distinction of the National System of Researchers (2009-2012) for its lines of work, occupational health, working conditions, education and gender.

Citation: Rafael Espinosa de los Monteros López, et.al. "The Communication As a Key Success in the Mexican Company "Frontera Imports" Located in the Territory US" International Journal of Managerial Studies and Research (IJMSR), vol 8, no. 7, 2020, pp. 25-32. doi: http:// dx.doi.org/10.20431/23490349.0807003.

Copyright: (C) 2020 Authors. This is an open-access article distributed under the terms of the Creative Commons Attribution License, which permits unrestricted use, distribution, and reproduction in any medium, provided the original author and source are credited. 